\title{
Frog in a Well
}

\author{
Frank W. Schwartz
}

Online veröffentlicht: 2.11 .2015

(C) Springer-Verlag Berlin Heidelberg 2015

Asian cultures usually have some version of the story about the frog in a well. In China, the story revolves around a sea turtle that visits a frog living in a shallow well. The frog proudly shows his lovely home, the circular view of the sky, and his happiness in being the lord of the well. He is shocked and surprised when the turtle describes the oceanic world - immense and complicated — a different place.

Reflecting on my wonderful experiences at the $2014 \mathrm{FH}-$ DGG meeting and other travels to Germany, I thought about the frog in the well on several different levels.

In Germany, rainfall averages $\sim 780 \mathrm{~mm}$ per year and well able to take care of all of the water needs for a stable population of about 80 million people. Indeed, the science that is reported in Grundwasser and elsewhere reflects a research community that has been largely insulated from the massive groundwater problems of other countries. Germany's total annual groundwater production of $5.8 \mathrm{~km}^{3}$ is miniscule compared to other countries that count on irrigated agriculture for food production. For the United States, groundwater withdrawals total about $112 \mathrm{~km}^{3} / \mathrm{yr}$ with production from just one aquifer - the High Plains system about $10 \mathrm{~km}^{3} / \mathrm{yr}$. The over-production of groundwater worldwide has created enormous local impacts causing a loss of surface waters, destruction of riparian ecosystems, and land subsidence. The coming shortages have the potential to change societies in unimaginable ways.

From a social perspective, Germany is wonderfully placed, without the burden of groundwater problems of for example, a populated Southeast Asia, a dry Middle East,

Dr. F. W. Schwartz, Ph.D. ( $\varangle)$

School of Earth Sciences, The Ohio State University, Columbus, US

e-mail: schwartz.11@osu.edu or a country like Australia that makes its living on exporting agricultural products and natural resources in a climate decidedly hostile to such activities. Yet, a research community growing up without big problems runs a risk of being parochial and inwardly looking - frogs in a well. For example, my look at the papers in Grundwasser discovered a broad swath of researchers working with a decidedly German focus on classical problems, e.g., karst, aquifer testing, brown-coal geochemistry, and technical problems related to energy in the subsurface.

There are of course larger Helmholtz and EU-wide programs looking at broad issues, like Water Resources Management. That strong research consistently produces papers for top tier journals. Yet, coming with these large programs is the difficult problem of organizing for innovation. From what I see, Germany and the EU follow the usual funding model for large projects, chopping the budget into "bitesized pieces" to let groundwater people do their small pieces, the ecologists study their frogs and bugs, and the French do pieces as well. These funding models typically produce good groundwater science; but absent significant integration the hydrogeologists remain frogs in a well.

Fundamentally, groundwater is a relatively small field that has largely run out of foundational science. It stays alive mostly by sorting out complexities in systems and parameters, or by solving problems relevant to local issues. Leading journals like Water Resources Research, once so groundwater focused, have moved away to surface water, watersheds and global ecology. Journals with groundwater as their name and major focus (Groundwater, Hydrogeology Journal, Grundwasser) have become the newest frogs in a well. These journals will survive and serve some useful purpose - yet, it is difficult to envision pathways for growth and diversification when stuck in a well. 
Those working in research institutes and at universities in particular can and do wake up some days and substantially change their research directions. Around the world and in Germany too, important thought leaders have said good-bye to classical groundwater science in a pattern of diversification that looks like Water Resources Research. Quite literally, some frogs are leaving the wells behind and heading for nearby ponds. 